\title{
Evaluation on the fatigue behavior of sand-blasted AlSi10Mg obtained by DMLS
}

\author{
Annalisa Pola, Davide Battini, Marialaura Tocci, Andrea Avanzini, Luca Girelli, Candida \\ Petrogalli, Marcello Gelfi \\ Department of Mechanical and Industrial Engineering, University of Brescia, Via Branze 38, 25123, Brescia, Italy \\ annalisa.pola@unibs.it,.bttp://orcid.org/0000-0002-0722-6518 \\ davide.battini@unibs.it,bttp://orcid.org/0000-0002-2044-5985 \\ m.tocciunibs.it,http://orcid.org/0000-0002-7515-0615 \\ andrea.avanzini@unibs.it, bttp://orcid.org/0000-0002-7188-7687 \\ l.girelli005@unibs.it, bttp://orcid.org/0000-0002-7630-0662 \\ candida.petrogalli@unibs.it,bttp://orcid.org/0000-0002-1774-3914 \\ marcello.gelfi@unibs.it, bttps://orcid.org/0000-0002-8939-811X
}

\section{ABSTRACT.}

Fatigue tests were performed on sand-blasted AlSi10Mg samples produced by Direct Metal Laser Sintering (DMLS) of powders. The effect of sand-blasting on surface properties was evaluated by roughness and residual stresses measurements, together with morphological analysis, in comparison with asfabricated condition. An evident improvement of surface finishing was observed after sand-blasting, which also lead to the presence of compressive residual stress on the external surface of samples, as revealed by XRD measurements. Furthermore, defects analysis allowed the identification of a uniform distribution of porosities in the cross section whereas larger porosities seem more abundant close to the surface. It was found that the tested material exhibits good fatigue resistance, supporting the positive role of sand-blasting as a simple post-processing treatment. Superficial defects are the preferential crack initiation sites, as demonstrated by SEM analysis of

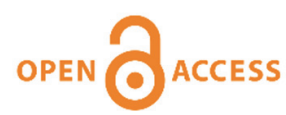

Citation: Pola, A., Battini, D., Tocci, M., Avanzini, A., Girelli, L., Petrogalli, C., Gelfi, M., Evaluation on the fatigue behavior of sand-blasted AlSi10Mg obtained by DMLS, Frattura ed Integrità Strutturale, 49 (2019) 775-790.

Received: 16.05.2019

Accepted: 18.06 .2019

Published: 01.07.2019

Copyright: (C)2019 This is an open access article under the terms of the CC-BY 4.0, which permits unrestricted use, distribution, and reproduction in any medium, provided the original author and source are credited.

KEYWORDS. AlSi10Mg; DMLS; Fatigue; Porosity; Sand-blasting; Scanning Electron Microscopy.

\section{INTRODUCTION}

dditive manufacturing (AM) for metallic materials is an innovative but already well established production technology able to merge different advantages, as such as the possibility of obtaining very complex shaped parts, with limited mass loss during their fabrication, and characterized by excellent mechanical properties [1-3]. 
There are several AM methods available on the market and the same process can be indicated with different nomenclatures mainly according to the machine producer and brand [1,4]. These processes can be applied with different engineering materials like stainless steel and titanium [5-8], cobalt-chromium and nickel alloys [9-11] but also copper [12-13] and aluminum alloys [14-15] or, rarely, gold [16].

Compared to other metals, the production of aluminum alloys parts via AM needs specific accuracy, due to the high reflectivity and thermal conductivity of $\mathrm{Al}$, like higher laser power $[14,17][18]$. Nevertheless, the use of aluminum alloys in $\mathrm{AM}$ is increasing thanks to their high strength to density ratio, that makes them attractive for automotive and aircraft sector $[3,19]$ as well as for space field, where many parts are already done and envisioned for future missions [20].

Among $\mathrm{Al}$ alloys, the most widely used and investigated is AlSi10Mg alloy, that shows interesting mechanical properties, in both as-fabricated and heat treated conditions [21-26], as well as good corrosion resistance [27-29]. Since during their life many parts undergo cycling loading conditions, several authors investigated also the fatigue behavior of this alloy in various conditions, evaluating the effect of fabrication direction or laser scanning strategy [26, 30-32].

$\mathrm{AM}$ products, in $\mathrm{Al}$ alloys as well as in other metals, can suffer from defects like porosity, residual stress and poor finishing that can negatively affect their performance [33-34]. It is known, in fact, that AM components are characterized by the presence of porosity due to many factors: melt splashing and Marangoni flow during laser scans, gas entrapment due to vaporization of low melting point constituents in the alloy, shrinkage porosity formed during solidification, lack of fusion caused by a poor overlap of melting pools [2, 15, 35-36]. For what concerns residual stresses, they are induced by the locally concentrated energy input, which determines large thermal gradients that result, in turn, in part deformations or even cracks [37-38]. Regarding the rough surface, this is related to the "stair step" effect, i.e. the stepped approximation by layers of curved and inclined surfaces, and by the "balling" phenomenon that causes the formation of discontinuous tracks and prevents a uniform deposition of new powder layer, also inducing porosity and delamination because of the poor inter-layer bonding [39-40].

Failure of AM parts is commonly related to the presence of the above mentioned surface and subsurface defects [41], as they are easily responsible for crack initiation during fatigue loading [26]. Therefore, post-treatments like machining and polishing, are frequently proposed on AM components in order to increase their life as they can help eliminating the influence of surface and subsurface imperfections [42]. Hence, different authors concentrated their attention on the fatigue resistance of machined samples compared to the as-fabricated condition [26, 30, 43]. Romano et al. [41], for instance, performed a statistical analysis of defects in AlSi10Mg, developing a model for fatigue life estimation in High Cycle Fatigue regimes taking into account the initial defects.

It is worth noting that one of the main benefits of AM is the opportunity of obtaining (near)net shape parts, without the need of machining operations, which could also be hardly feasible for some geometries. Therefore, other surface treatments not involving machining or polishing can result advantageous. In this regard, some authors investigated the effect of sandblasting or shot-peening on fatigue enhancement of AlSi10Mg alloy [44-46]. In particular, in [45] sand-blasting and shotpeening were demonstrated to remarkably improve fatigue strength compared to as-fabricated specimens. In [44] the effect of different shot-peening conditions (steel or ceramic balls) was also analyzed. The authors found that the surfaces polishing before this post-treatment or the subsequent removal of material of about 25-30 $\mu \mathrm{m}$ from the surface improved fatigue resistance. In [46], an insight on how shot peening changes superficial and sub-superficial pore morphology and the observed increase in low-cycle and high-cycle fatigue strength was presented.

However, notwithstanding the already recognized influence of surface post-treatments on fatigue resistance of AM parts, the current knowledge about its effectiveness is still incomplete. Hence, in this paper a thorough investigation of fatigue properties of Direct Metal Laser Sintered (DMLS) AlSi10Mg alloy after sand-blasting is performed, correlating the fracture mechanism to the microstructure.

\section{MATERIALS AND METHODS}

$\mathrm{T}$ he AM specimens were produced by DMLS method using an EOS M290 system (400 W, Yb laser fibre; F-theta lens; $30 \mathrm{~A}$ and $400 \mathrm{~V}$ power supply; $7000 \mathrm{hPa}, 20 \mathrm{~m}^{3} / \mathrm{h}$ inert gas supply; $100 \mu \mathrm{m}$ focus diameter; EOS GmbH Electro Optical System [47]). They were built along the vertical direction with a layer thickness of $30 \mu \mathrm{m}$, using a building platform pre-heated at $80^{\circ} \mathrm{C}$ in argon atmosphere. The used powder is the commercial EOS Aluminium AlSi10Mg, whose nominal composition is reported in Tab. 1.

In order to perform a morphological analysis of powders, two samples of AlSi10Mg powder were taken. The first sample was deposited on a tape and observed by means of LEO EVO 40 scanning electron microscope (SEM). The second sample was mounted in an epoxy resin, polished on abrasive papers and observed by Leica DMI $5000 \mathrm{M}$ optical microscope. 


\begin{tabular}{cccccccccccc}
\hline & $\mathrm{Si}$ & $\mathrm{Mg}$ & $\mathrm{Cu}$ & $\mathrm{Fe}$ & $\mathrm{Mn}$ & $\mathrm{Ni}$ & $\mathrm{Zn}$ & $\mathrm{Pb}$ & $\mathrm{Sn}$ & $\mathrm{Ti}$ & $\mathrm{Al}$ \\
$\mathrm{AlSi10Mg}$ & $9-11$ & $0.2-0.45$ & $<0.05$ & $<0.55$ & $<0.45$ & 0.05 & $<0.10$ & $<0.05$ & $<0.10$ & $<0.15$ & Balance \\
\hline
\end{tabular}

Table 1: Nominal chemical composition (wt. \%) of the commercial EOS Aluminium AlSi10Mg powder.

In Fig. 1, the geometry of the specimens used for tensile (Fig.1a) and fatigue (Fig.1b) tests is shown.

After manufacturing, the samples were sand-blasted by using the B120 Microblast Ceramic Beads of Saint-Gobain Zirpro at about $10 \mathrm{~cm}$ from the nozzle and for an exposure time of $2 \mathrm{~min}$ at $5 \mathrm{bar}$. The sand particles had a size distribution in the range of $63-125 \mu \mathrm{m}$. Their chemical composition, performed by X-ray fluorescence on melting sample by the producer, is reported in Tab. 2.

The samples roughness $\left(\mathrm{R}_{\mathrm{a}}\right.$ ) was measured before and after sand-blasting by a stylus profilometer (Tribotechnique) with a tip radius of $5 \mu \mathrm{m}$ and an applied load of $1 \mathrm{mN}$.
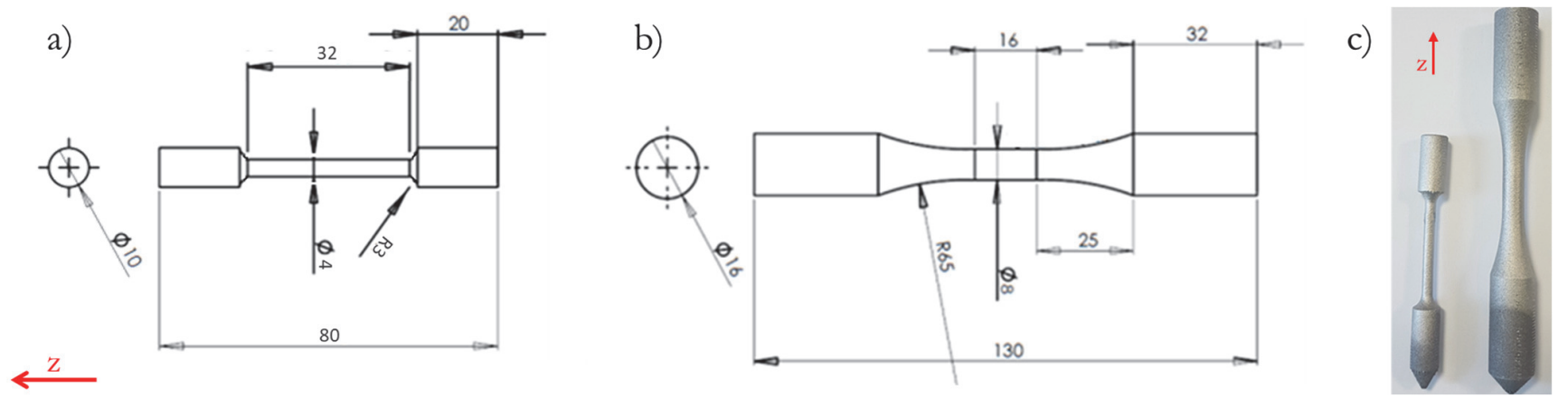

Figure 1: Specimen geometry for (a) tensile test and (b) fatigue test samples and (c) produced specimens

\begin{tabular}{ccc}
\hline & Min \% & Max \% \\
$\mathrm{ZrO}_{2}$ & 60 & 70 \\
$\mathrm{SiO}_{2}$ & 28 & 33 \\
$\mathrm{Al}_{2} \mathrm{O}_{3}$ & 0 & 10 \\
\hline
\end{tabular}

Table 2: Nominal chemical analysis (wt. \%) of the particles used for sand-blasting.

A preliminary microstructural analysis was performed by optical (Leica DMI 5000M) and scanning electron (LEO EVO 40) microscope. To this aim, the samples were cut perpendicularly to the fabrication direction, polished up to mirror finishing and etched with Keller's reagent ( $1 \% \mathrm{HF}, 1.5 \% \mathrm{HCl}, 2.5 \% \mathrm{HNO}_{3}$ and $\left.95 \% \mathrm{H}_{2} \mathrm{O}\right)$, applied for $30 \mathrm{~s}$ according to ASTM E407 standard [48].

A detailed defect analysis was carried out on four specimens to characterize the distribution of porosity. To this aim, a cylindrical specimen, with a length of $10 \pm 2 \mathrm{~mm}$, was obtained from the gage length of four sand-blasted AlSi10Mg fatigue samples performing a double cut, perpendicularly to the axis of the sample, with a Struers Labotom machine. The specimen was ultrasonically cleaned in ethanol, dried and inserted in a cold mounting resin. After the solidification of the resin, the mounted specimen was grinded and polished up to mirror finishing, starting from P220 grinding paper till to a velvet cloth with Struers colloidal silica suspension. Finally, the specimen was ultrasonically cleaned in ethanol and dried with warm air. The optical analysis was performed by means of Leica DMI 5000 optical microscope mapping the whole polished section of the specimens with $120 \pm 5$ images at a magnification of 50x. The entire section was reconstructed with the support of the Leica Application Suite v4.8 software. The whole sections were processed using a custom software for defects analysis coded within NI Labview environment that evolved from previous approaches used for marker tracking [49] and crack length tracking [50] during various experimental tests. This new optical measurement code allows the processing of single or multiple images and provides a text output file containing all the data of the most significant features of each defect identified in the image(s) such as: position, bounding box, orientation, elongation, area, maximum Feret diameter, and many others. High resolutions images (over $100 \mathrm{Mpx}$ ) and high numbers of defects per image can be handled with ease. 
The software operates through blob analysis of binarized images and offers the user the possibility of tailoring many processing settings in order to enhance defect identification and feature output:

- pre-binarization settings: user can extract color plane, tweak the BGC (brightness, gamma, contrast) settings or even apply a convolution filter with standard or custom kernels;

- binarization settings: global, local, or custom thresholding algorithms are available;

- post-binarization settings: basic and advanced morphological operations are available, as well as various filtering methods based on feature values or even defect aggregation algorithms.

Everything is provided with a proper GUI (graphical user interface) where the user can see the processed image in real-time and save both the processed image and the features of all the defects which can also be conveniently plotted and handled via custom Matlab code.

Room temperature tensile tests were performed according to UNI EN ISO 6892-1 standard using an Instron 3369 testing machine with a $50 \mathrm{kN}$ load cell. The elongation was monitored using a knife-edge extensometer (length of $25 \mathrm{~mm}$ ) fixed to the gauge length of the samples. Four specimens were tested, at different crosshead speeds resulting in strain rates ranging from $0.000167 \mathrm{~s}^{-1}$ to $0.015 \mathrm{~s}^{-1}$.

Concerning the fatigue tests, they were performed at room temperature at different peak stress levels on a load-controlled servo-hydraulic testing machine (Instron 8501) with a stress ratio $\left(\mathrm{R}=\sigma_{\min } / \sigma_{\max }\right)$ set to zero and frequency $20 \mathrm{~Hz}$. Eighteen tests were carried out. The specimens were loaded until failure or until $2 \times 10^{6}$ cycles (taken as infinite life) were reached.

Experimental data were processed according to the ISO 12107 standard: the stress and life were linearly interpolated in log$\log$ coordinates and the fatigue strength was estimated via the staircase method.

In order to investigate fatigue strength for both finite and infinite life regimes, peak stress levels were selected as no preliminary knowledge of the material fatigue behavior was available. For the S-N test (cyclic stress, S, versus the number of cycles to failure, N), the guidelines reported in [51] were followed. These rules are based on the method proposed in [52] for statistical evaluation of S-N, according to which:

- a minimum of 2 tests on 4 different stress levels for the finite fatigue life regime and

- a minimum of 6 tests for a simplified staircase for the infinite fatigue life regime

are needed.

Specifically, $12.5 \mathrm{MPa}$ for the finite life curve and $5 \mathrm{MPa}$ for the infinite life curve were chosen as fixed $\Delta \sigma$. From this set of data, the slope of the S-N curve in the finite life region was calculated via linear regression and an estimate of fatigue strength was obtained by applying a reduced staircase method.

The fractured surfaces of fatigue test samples were observed by LEICA 300 digital microscope and LEO EVO 40 scanning electron microscope (SEM) equipped with an Oxford energy dispersive spectroscopy (EDS) probe for elemental analysis. In order to estimate the residual stress induced by the sand-blasting treatment, which is known to affect stress state of the surface and consequently the fatigue behavior, a comparative analysis of residual stress on both as-fabricated and sandblasted surface was carried out for a couple of specimens by X-Ray Diffraction (XRD) technique. The measurements were performed by a Bruker D8 Discover XRD 2 diffractometer ( $\mathrm{Cu}-\mathrm{K} \alpha$ radiation), equipped with a beam collimator of $0.5 \mathrm{~mm}$ in diameter. The $\sin ^{2} \psi$-method was applied in omega-mode configuration on the (331) plane of aluminum with tilting angle (psi) from -60 to $+60^{\circ}$.

\section{RESULTS AND DISCUSSION}

\section{Metallographic characterization}

he morphology of used powders is shown in Fig. 2. Particles show a spherical shape and several satellites are present. At times, small pores can be detected inside the particles (Fig. 2b).

In Fig. 3a the microstructure of the AM samples along the building plane (xy) is shown after Keller's etching. The melting pools elongated in the deposition plane can be observed, also revealing the underneath layers formed at different orientations as a consequence of the printing strategy. In agreement with the literature, at the pool boundary a coarser microstructure rich in $\mathrm{Al}$ can be detected [53].

The microstructure along the building direction $(z)$ is reported in Fig. 3b. Similarly, the melt pools are clearly visible, in this case with the typical half cylindrical shape. Again, they are characterized by a fine core, surrounded by a coarser boundary zone. This is confirmed by the analysis performed at higher magnification (Fig. 3c), where $\alpha$-Al cellular grains (dark areas) surrounded by superfine Si network (light areas) are visible, according to the literature [1, 25, 29, 54].

Small porosities were also noticed due to the AM technique [14-15, 35, 55-56]. 

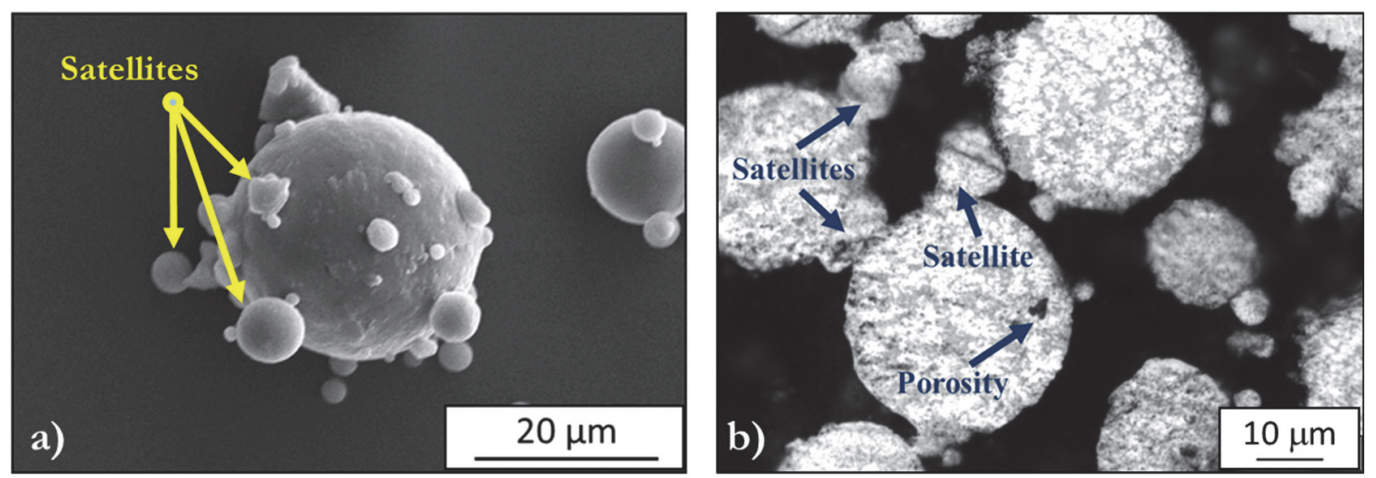

Figure 2: SEM (a) and optical (b) images of AlSi10Mg alloy powders.
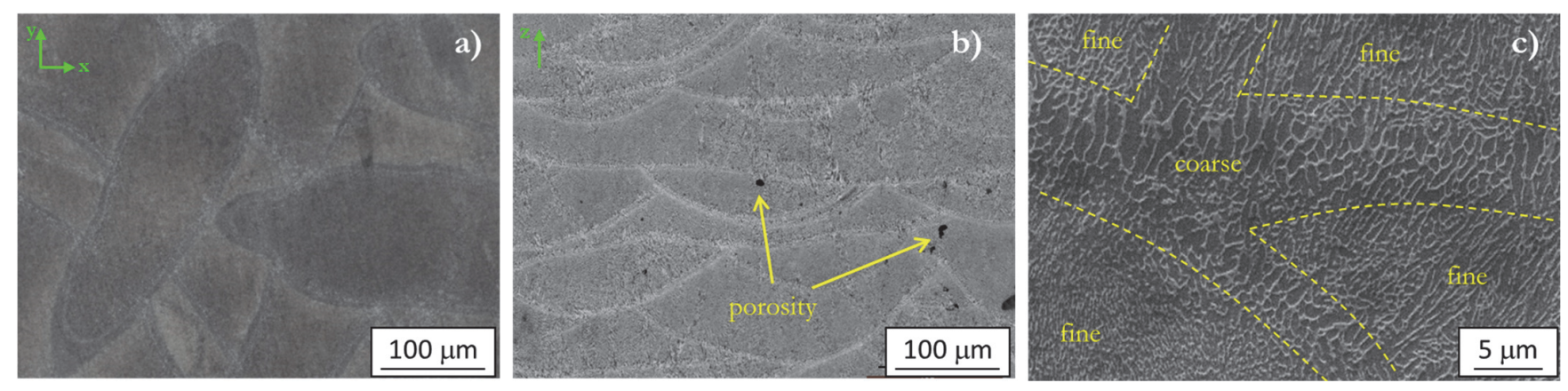

Figure 3: Microstructure of AlSi10Mg DLMS samples performed by optical microscopy on (a) horizontal and (b) vertical directions and (c) by SEM after Keller's etching

An example of the surface morphology of the as-fabricated as well as sand-blasted samples is provided in Fig. 4. The asfabricated surface appears irregular, with a lot of satellites and/or balling, as it frequently happens in as-produced parts [43]. On the contrary, the sand-blasted sample shows a more homogeneous surface, with remarkably reduced imperfections, even though small porosities can be revealed.
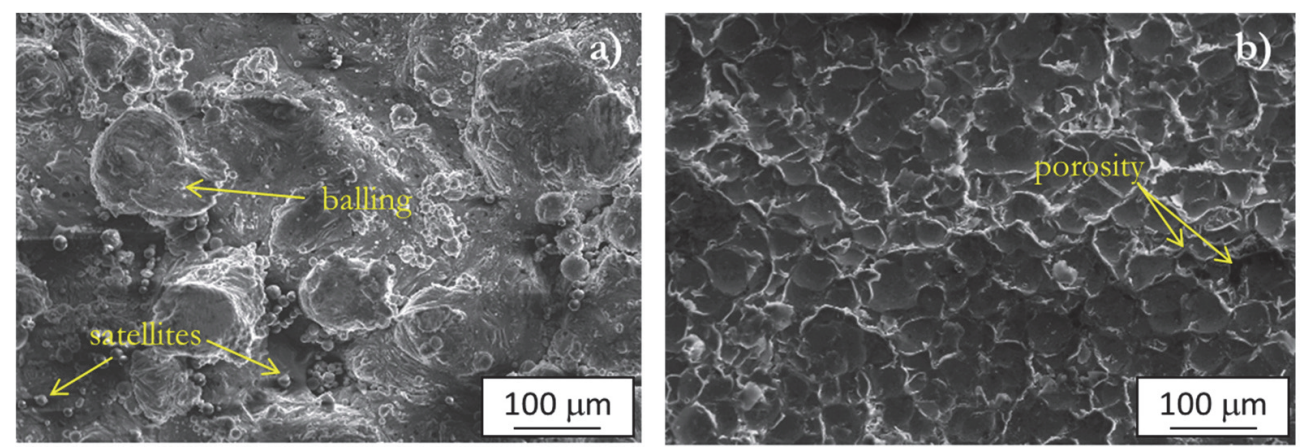

Figure 4: Surface morphology of (a) as-fabricated and (b) as sand-blasted samples

\section{Residual stress}

As expected, sand blasting significantly affects the surface roughness $\mathrm{R}_{\mathrm{a}}$ of the studied material, as shown in Tab. 3. In fact, this post-treatment determines a strong decrease of the surface roughness $\mathrm{R}_{\mathrm{a}}$ as compared to the as-fabricated condition (approximately a reduction of $50 \%$ ). The values measured in the present study are in good agreement with the results of other authors [45], who studied the effect of sand blasting on the same alloy. The reduction in surface roughness after sand blasting is due to the effective removal of the superficial imperfections that characterize AM materials (satellites, balling, 
partially melted particles, open porosities). This is further supported by the SEM images of the samples surfaces before and after sand blasting, as above discussed.

\begin{tabular}{cc}
\hline & $\mathrm{R}_{\mathrm{a}}(\mu \mathrm{m})$ \\
As-fabricated & $13.2 \pm 2.1$ \\
Sand-blasted & $7.0 \pm 1.2$ \\
\hline
\end{tabular}

Table 3: Roughness measurements before and after sand-blasting.

As a consequence of this post-treatment, a significant difference in microstructure and residual stress level has been produced on the samples surface. The XRD images collected from samples before and after sand-basting show the change of Debye rings shape of aluminum phase, which passed from a spotty to a smooth appearance (Fig. 5). This is likely due to the plastic deformation and strain hardening induced by the repeated impact of sand particles on samples surface, which reduced the diffracting crystallites size and also modified the residual stress state [57]. In particular, the as-fabricated samples showed a tensile stress of $76 \mathrm{MPa} \pm 10 \mathrm{MPa}$ (without shear stress), due the high cooling rates related to the specific manufacturing processing, as well documented in scientific literature [37]. Instead, after sand-blasting, a compression residual stress of $-105 \mathrm{MPa} \pm 2 \mathrm{MPa}$ was measured on the samples surface, again without shear stress. This is expected to positively affect the alloy fatigue behavior, as demonstrated by several authors [44-46]. Additionally, the measured values are in good agreement with the findings of other researchers about AlSi10Mg alloy in as-fabricated and sand-blasted condition [45], even though, in their paper, higher compressive stresses, up to approximately $150 \mathrm{MPa}$, were also measured at about $0.1 \mathrm{~mm}$ from the surface.

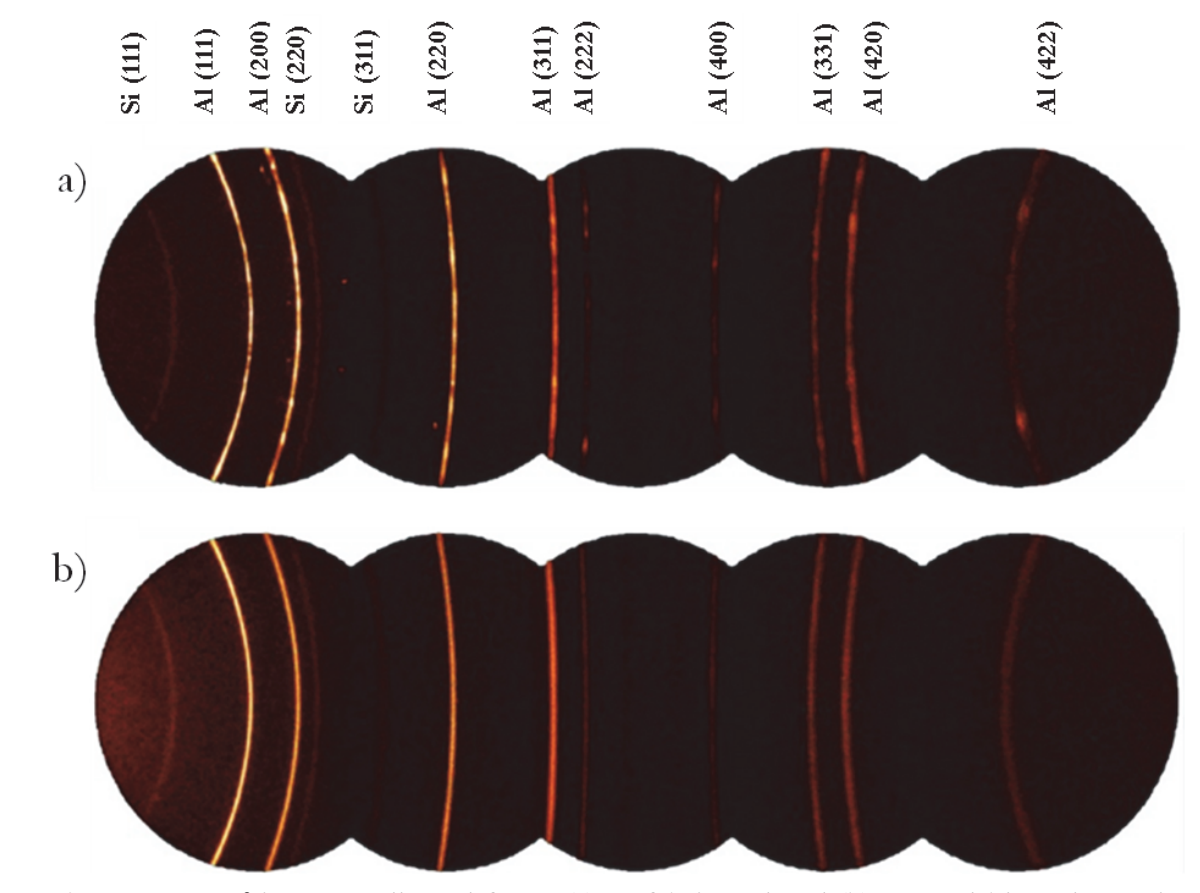

Figure 5: XRD ${ }^{2}$ images collected from: (a) as-fabricated and (b) as sand-blasted samples

\section{Defects analysis}

An example of the reconstructed sections of analyzed sand-blasted specimens is reported in Fig.6a.

The typical microstructure constituted by the melting pools can be recognized in all the sections, where the scanning strategy is clearly noticeable. As already shown, the sand-blasting surface treatment reduced the roughness of the samples in comparison with the as-produced one, easily decreasing the possibility of the fatigue crack initiation at the external surface. A significant presence of small internal porosity can be found in all the analyzed sections, that are known to be due to different phenomena related to the quality of the powder (intrinsic porosity, as shown in Fig. 2b, and moisture) as well as 
to the process itself (as such as argon entrapment, oxide inclusions, melt splashing, Marangoni flow, that induce almost spherical defects, but also shrinkage and lack of fusion porosities, that show an irregular morphology) [2, 15, 35-36].
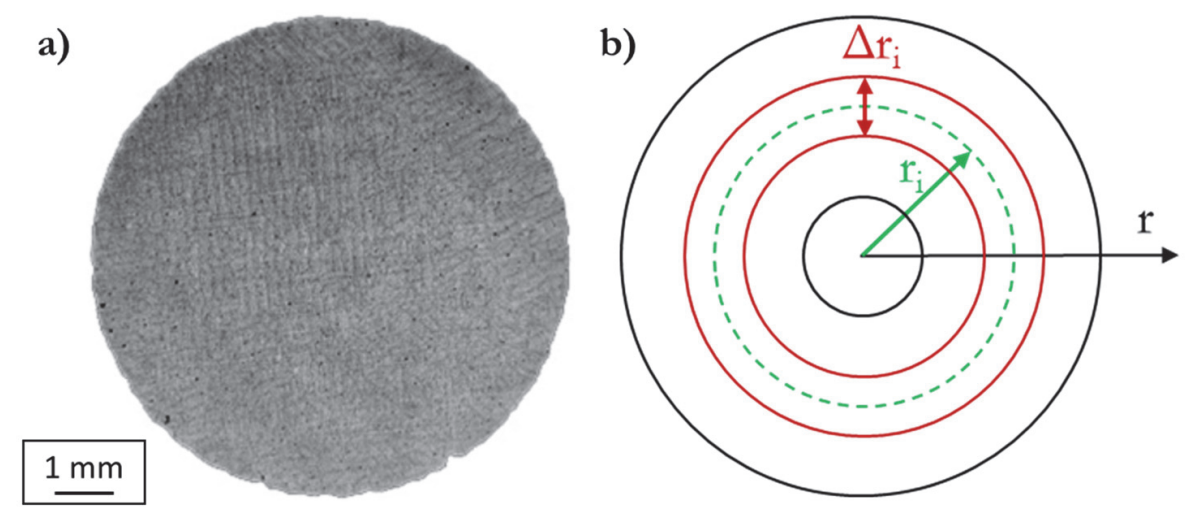

Figure 6: Reconstructed sections of (a) sand-blasted AlSi10Mg sample and (b) sketch of the rings definition

The image analysis was carried out with the application of a data binning technique on defect data to group them in 12 radial coordinate intervals (rings) that generate 12 concentric rings, each with a mean radius $r_{i}$ (Fig. 6b) and a fixed $\Delta r$.

In Fig. 7a, the distribution of defects obtained via image analysis is reported as a function of the distance from the section center. It can be noted that all the samples show a higher porosity count in regions close to the external surface, with a linear trend of porosity count inside a generic ring area $\left(\left.A_{\text {RING }}\right|_{r_{i}}\right)$ with respect to the average radius $r_{i}$ of the ring. The same linear trend can also be seen in the increase of the ring area $\left.A_{\text {RING }}\right|_{r_{i}}$ with respect to its average radius $r_{i}$, since:

$$
d A(r)=\left.2 \pi \cdot r \cdot d r \stackrel{\int_{d A}}{\Rightarrow} A_{\mathrm{RING}}\right|_{r_{i}}=\pi\left[\left(r_{i}+\frac{\Delta r}{2}\right)^{2}-\left(r_{i}-\frac{\Delta r}{2}\right)^{2}\right]=2 \pi r_{i} \Delta r
$$

As a result, the density of porosities (number of porosities per unit of cross-section area) appears non-dependent on the distance from the specimen axis $(r)$.

Alternatively, the same conclusion can be obtained (with even added evidence) by observing that the cumulative of the number of defects shows a quadratic trend with respect to the average radius $r_{i}$ (Fig. 7b). For these reasons, the radial defect distribution showing a higher number of defects close to the external surface of the specimen seems non-related to the manufacturing process but solely to a geometric effect.
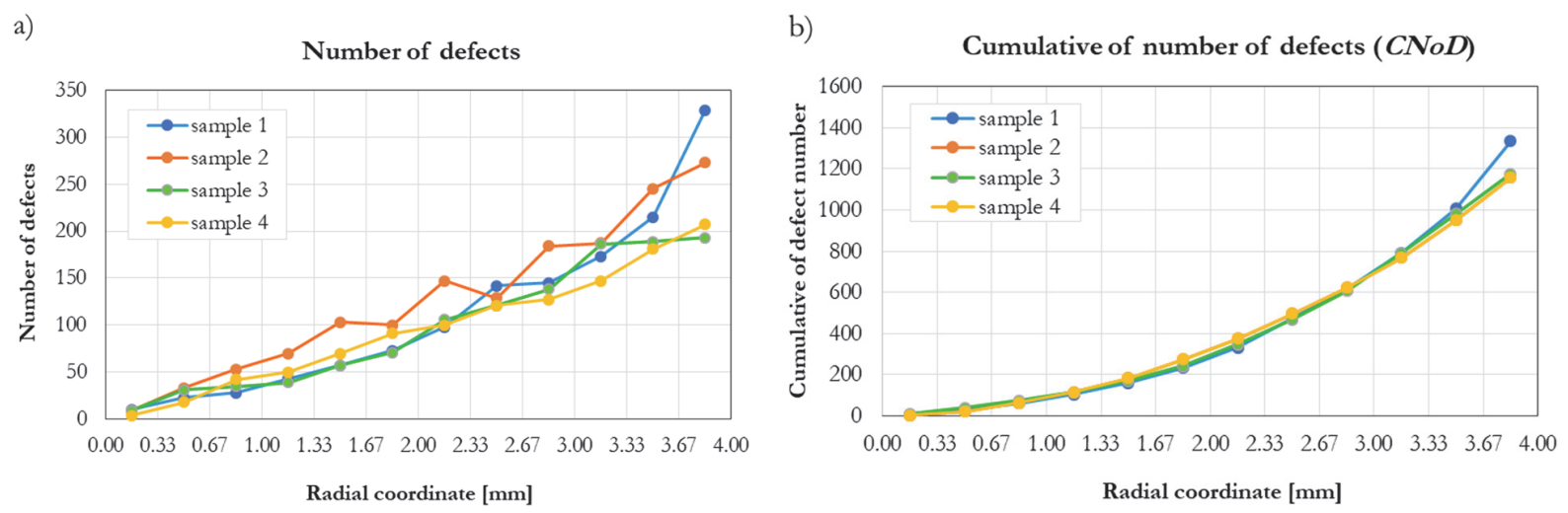

Figure 7: (a) Number of defects for each radial coordinate bin and (b) cumulative of the number of defects.

Considering defect dimensions, it can be noticed that the average defect area (ADA) appears to be constant (Fig. 8a) with respect to the radial coordinate, showing again that the manufacturing process led to a fairly uniform radial distribution of 
porosities. This peculiarity can also be observed as the predictable quadratic trend of the cumulative sum of defect areas (CSDA) with respect to radial coordinate (Fig. 8b) since:

$$
\operatorname{CSD} A(r)=A D A * \operatorname{CNoD}(r)
$$

where $C N o D(r)$ is the cumulative number of defects as function of the radial coordinate (Fig. 7b).

a)

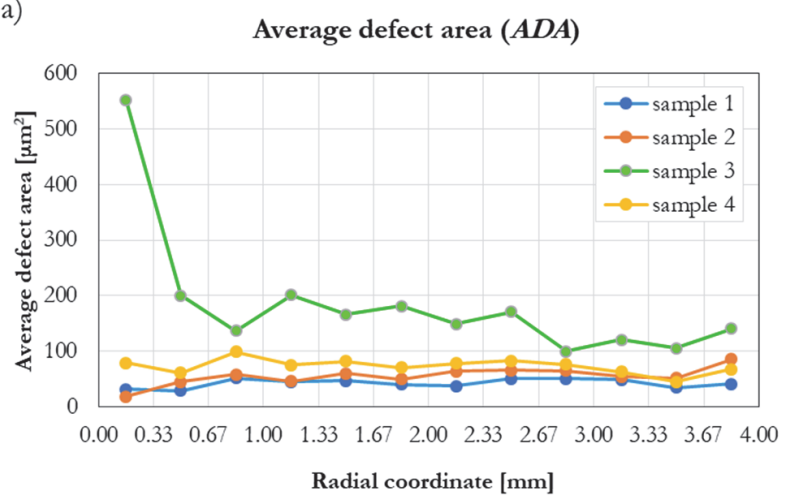

b)

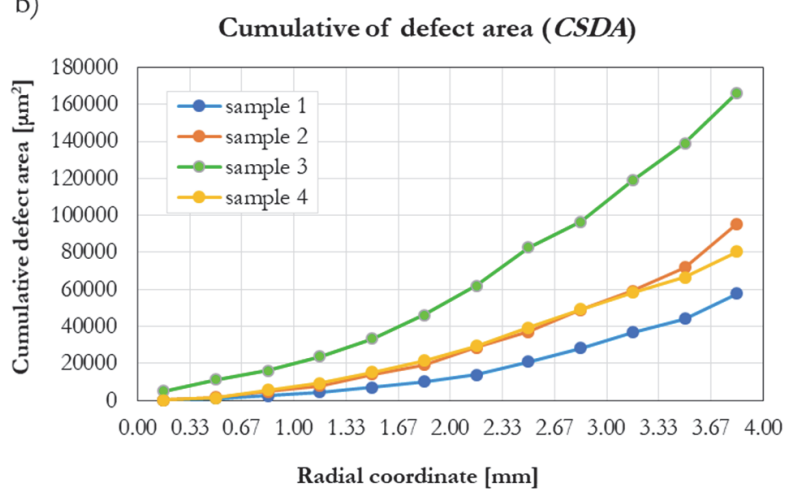

Figure 8: (a) Average defect area for each radial coordinate bin and (b) cumulative of the defect area.

On the other hand, the analysis of defect dimensions on the four cross-sections (Fig. 9) also shows that, in general, the most critical defect is very close to the external surface (with only one sample having a bigger defect in the core). Specifically, the most significant defects result with maximum Feret diameter in the range of 70-130 $\mu \mathrm{m}$ and are located within a 200-300 $\mu \mathrm{m}$ sub-superficial layer.

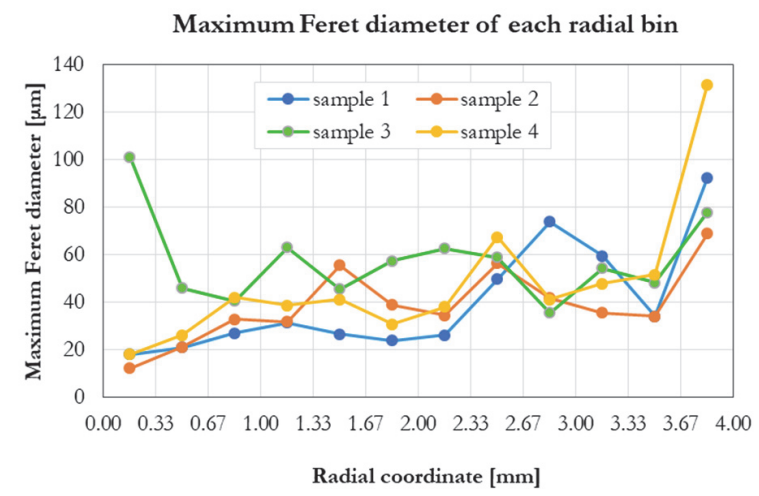

Figure 9: Maximum Feret diameter for each radial coordinate bin.

\section{Tensile test}

The results of tensile tests are summarized in Tab. 4.

Both the yield strength and the ultimate strength, as well as the elastic modulus, are in good agreement with the data reported by several authors for as-fabricated AlSi10Mg [30, 43, 57]. As noticeable by the obtained data, no strain rate dependency seems to be present in the analyzed range.

\section{Fatigue test}

The results of fatigue tests are summarized in Fig. 10, in the form of a traditional Smax-N curve with $\log$-log coordinates with $S_{\max }$ being the peak stress of the loading cycle.

The lower limits of the $\mathrm{S}_{\max }-\mathrm{N}$ curve in both the finite and infinite life regimes were determined as the probability of $90 \%$ of the future population to fail with a $90 \%$ confidence (lower confidence limit, LCL). Specifically, fatigue strength resulted 
approximately $96 \mathrm{MPa}$ with a lower limit of $86 \mathrm{MPa}$. Overall, despite the limited number of specimens, the Smax-N curve resulting from experimental data showed low dispersion.

\begin{tabular}{cccccc}
\hline & \multicolumn{5}{c}{ Strain rates } \\
& $0.0167 \% \mathrm{~s}^{-1}$ & $0.03 \% \mathrm{~s}^{-1}$ & $0.4 \% \mathrm{~s}^{-1}$ & $1.5 \% \mathrm{~s}^{-1}$ & Average \\
Young Modulus [MPa] & 57670 & 57600 & 57860 & 58870 & $58000 \pm 590$ \\
Yield Strength [MPa] & 254.4 & 252.9 & 246.5 & 248.6 & $250.6 \pm 3.7$ \\
Ultimate strength [MPa] & 421.5 & 418.9 & 406.7 & 381.5 & $407.2 \pm 18.3$ \\
\hline
\end{tabular}

Table 4: Results of tensile tests.

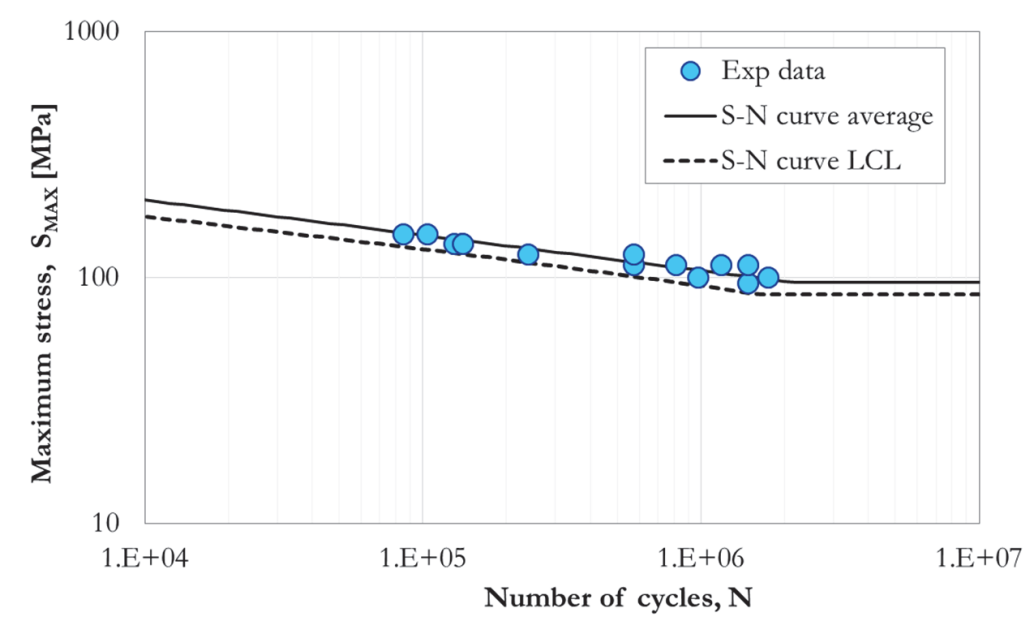

Figure 10: Results of fatigue test.

A comparison with published data can provide some interesting highlights. To this aim, the data reported in [26, 43] are particularly relevant, since fatigue tests were conducted on AM-AlSi10Mg under similar loading conditions (i.e. axial loading with $\mathrm{R}=0.1$ ) and included vertically-fabricated specimens, as in the present study. Therefore, for comparison purposes, relevant data were obtained from fatigue life diagrams of the above-mentioned studies by means of the software WebPlotDigitizer 4.1. Fig. 11 shows the digitized data to better appreciate similarities and differences with the findings of the present investigation. In the study of [43] (Fig. 11a), the effects of surface quality and heat treatment (HT) on fatigue performance for SLM AlSi10Mg were evaluated. None of the as-fabricated samples exceeded a predefined cut-off limit at $3 \cdot 10^{7}$ cycles even at the lowest maximum stress level examined of $63 \mathrm{MPa}$. Interestingly, machining the samples was found to play a minor role in improving the fatigue behavior compared to heat treatment, for which the same predefined cut-off limit was reached at a maximum stress of $94 \mathrm{MPa}$. The properties of the present sand-blasted material seem superior to those reported for as-fabricated by [43] but slightly lower when compared to machined or heat-treated specimens. On the other hand (Fig. 11b), considering data reported in [1] , the combination of platform heating plus T6 heat treatment showed a significant increase in fatigue resistance whereas every other test scenario led to results closer to our sand-blasted specimens. Some fatigue test data for machined samples of AlSi10Mg under uniaxial tension with stress ratio $\mathrm{R}=0.1 \mathrm{were}$ also reported in [58]. In this case though, only two stress amplitudes $\mathrm{S}_{\mathrm{a}}$ of 80 and $100 \mathrm{MPa}$ were considered, corresponding to a peak stress $\mathrm{S}_{\max }$ of 178 and $222 \mathrm{MPa}$. Fatigue life for machined specimens built in the $\mathrm{z}$ direction for $\mathrm{S}_{\mathrm{a}}=80 \mathrm{MPa}$ was reported being in the range of 120000 - 190000 cycles which is slightly higher than the specimens tested in the present work at $\mathrm{S}_{\mathrm{a}}=75 \mathrm{MPa}$.

Data for axial fatigue were also reported in [41] but referring to machined sample and stress ratio $\mathrm{R}=-1$. The alternating component of the loading cycle corresponding to our fatigue limit for sand-blasted specimens (approximately $48 \mathrm{MPa}$ ) is actually lower than values reported in that study. In this case, the comparison is less direct, since our fatigue testing was performed at $\mathrm{R}=0$, a more severe test setup, as the external loads always act as crack-openers, compared to fully reversed axial loading or rotating bending test, which might instead be a more typical load case in mechanical engineering. 

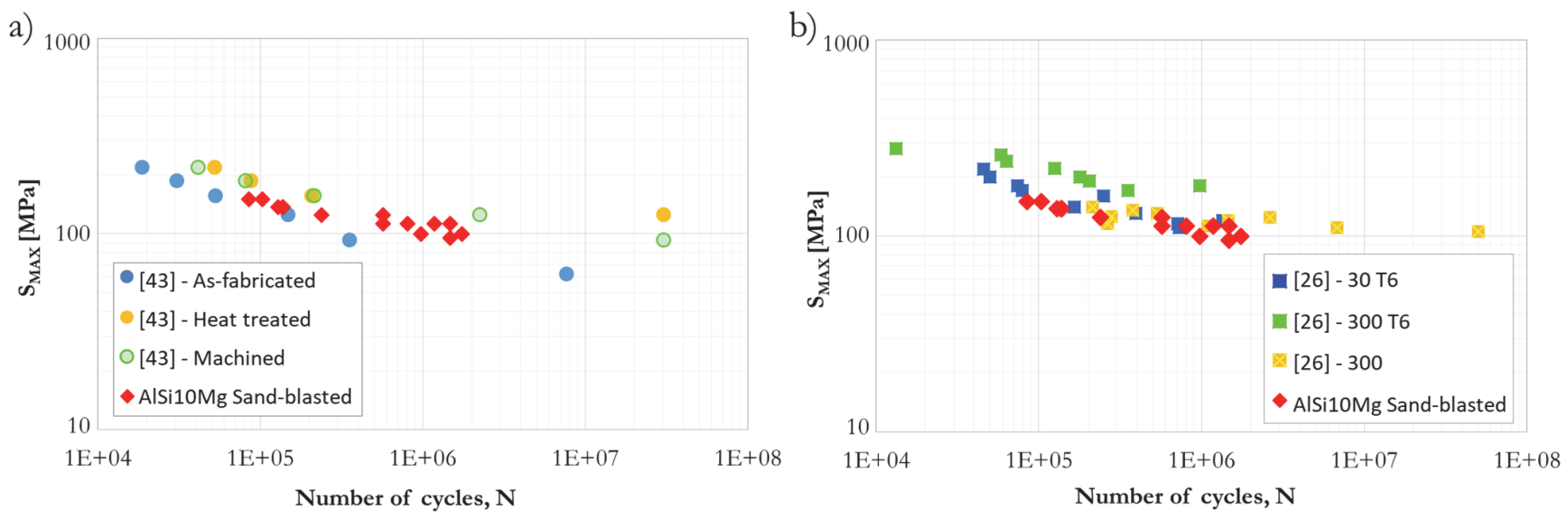

Figure 11: Comparison of fatigue tests (a) with [43] and (b) with [26].

The effects of surface treatment including shot-peening (SP) or sand-blasting (SB) on fatigue strength, in combination with heat treatments or specific machining strategies, were also investigated in literature. In [2] fatigue tests were carried out on specimens manufactured in vertical direction considering SB or SP and synergetic effects with heat treatments. Poor fatigue strength, as low as $50 \mathrm{MPa}$, was reported for as-fabricated specimens whereas both SB and SP determined a remarkable increase up to the 160-176 MPa range which is even higher than reported fatigue limits for cast alloys (76-115 MPa) and wrought $6061(120 \mathrm{MPa})$. Interestingly, the influence of heat treatment was found to be different for as-fabricated, SB and $\mathrm{SP}$ specimens. The effects of a sequence of treatments including machining, polishing and shot-peening on fatigue resistance of SLM-AlSi10Mg specimens were instead investigated in [44], where the tests were performed with a Moore rotating beam machine (RBM). Polishing the surface before SP or removing about 25-30 $\mu \mathrm{m}$ from the surface after SP showed to be beneficial for fatigue life with an order of magnitude of about $100 \mathrm{MPa}$ for treated samples. In [46] the porosity distribution and morphology of selective laser melted samples before and after SP were investigated by means of micro-tomography analysis. SP increased low- and high-cycle-fatigue resistance by $20 \mathrm{MPa}$, considering a fatigue strength limit set to $10^{7}$ cycles. Overall, these investigations showed that SB or SP represent a viable approach for improvement of fatigue resistance. In fact, the fatigue strength of SB specimens found during the present study is in general higher than fatigue properties for asfabricated condition reported in the above-mentioned studies even if the axial loading cycles at $\mathrm{R}=0$ are way more critical than fully reversed bending stress-cycles. This conclusion is also supported by results of data-fitting with Basquin's equation, expressed as per Eqn. 1 [59]:

$$
\mathrm{S}_{\mathrm{a}}=\mathrm{A}\left(\mathrm{N}_{\mathrm{f}}\right) \mathrm{B}
$$

where $\mathrm{S}_{\mathrm{a}}$ is the stress amplitude, $\mathrm{N}_{\mathrm{f}}$ is the number of cycles to failure, and $\mathrm{A}$ and $\mathrm{B}$ are constants. Taking base-ten logarithms provides:

$$
\log \left(\mathrm{S}_{\mathrm{a}}\right)=\log (\mathrm{A})+\mathrm{BLog}\left(\mathrm{N}_{\mathrm{f}}\right)
$$

The experimental results for finite life of the present study can be generally well interpolated by a linear regression line. In Tab. 5 results for the present study are compared with literature.

When comparing with other materials, smaller absolute B values (i.e. reduced slope) indicate an improvement of fatigue performance and this confirms again the usefulness of sand-blasting as a relatively simple treatment that can improve fatigue behavior of AM metal components.

\section{Fractured surface analysis}

The observation of fracture surface of fatigue samples at low magnification by digital microscope allows to reveal the presence of a large flat region, typical of fatigue propagation, with a small final overload area (Fig. 12). Several small porosities can be easily detected, which are known to be due to different phenomena as above reported.

The analyses at higher magnification performed by SEM are reported in Fig. 13-14. It can be clearly seen that the fatigue crack nucleated from defects at the surface and that the fracture initially moved slowly in radial direction till the distance shown in Fig. 13a with a dashed-line. Afterwards, the crack propagation became stable, as deducible from the characteristic 
repetitive fatigue striations (Fig. 13b-c), representing the crack propagation for each cycle of stress. Comparing the striations at the crack beginning (Fig. 13c) with those close to the end of crack propagation (Fig. 13d), it is evident the increase of striations inter-distance. This is the natural consequence of the progressive increase of stress intensity at the crack tip that accelerated the propagation rate in the last part of the failure. Moreover, the striations morphology is quite brittle, with signs of micro-cleavage, probably related to the presence of brittle superfine silicon particles (Fig. 13d). Other authors explained the presence of brittle striations as a consequence of high internal stresses in the material, induced by the production process [43].

\begin{tabular}{cccccc}
\hline & $\begin{array}{c}\text { Sample } \\
\text { treatment }\end{array}$ & Load type & $\begin{array}{c}\text { Stress } \\
\text { Ratio }\end{array}$ & B & $\log (\mathrm{A})$ \\
\hline Present Study & SB & Axial & 0 & $-0.13 \pm 0.01$ & $2.49 \pm 0.08$ \\
{$[3]$} & $\mathrm{AB}$ & Axial & 0.1 & $-0.22 \pm 0.02$ & $2.92 \pm 0.09$ \\
{$[3]$} & $\mathrm{M}$ & Axial & 0.1 & $-0.25 \pm 0.04$ & $3.1 \pm 0.2$ \\
{$[3]$} & $\mathrm{HT}$ & Axial & 0.1 & $-0.15 \pm 0.02$ & $2.7 \pm 0.1$ \\
{$[3]$} & $\mathrm{HT}+\mathrm{M}$ & Axial & 0.1 & $-0.25 \pm 0.02$ & $3.1 \pm 0.1$ \\
{$[4]$} & $\mathrm{MP}$ & $\mathrm{RBM}$ & -1 & $-0.20 \pm 0.01$ & $3.07 \pm 0.03$ \\
{$[4]$} & $\mathrm{M}+\mathrm{SP}$ & $\mathrm{RBM}$ & -1 & $-0.13 \pm 0.01$ & $2.77 \pm 0.05$ \\
{$[4]$} & $\mathrm{SP}+\mathrm{EP}$ & $\mathrm{RBM}$ & -1 & $-0.11 \pm 0.01$ & $2.73 \pm 0.05$ \\
{$[4]$} & $\mathrm{SP}+\mathrm{MP}$ & $\mathrm{RBM}$ & -1 & $-0.10 \pm 0.01$ & $2.79 \pm 0.06$ \\
\hline
\end{tabular}

Table 5: Fitting parameters of fatigue curve, where SB is sand-basted, AB as-fabricated, M machined, HT heat treated, MP mechanically polished, SP shot-peened, EP electrolytic polished.

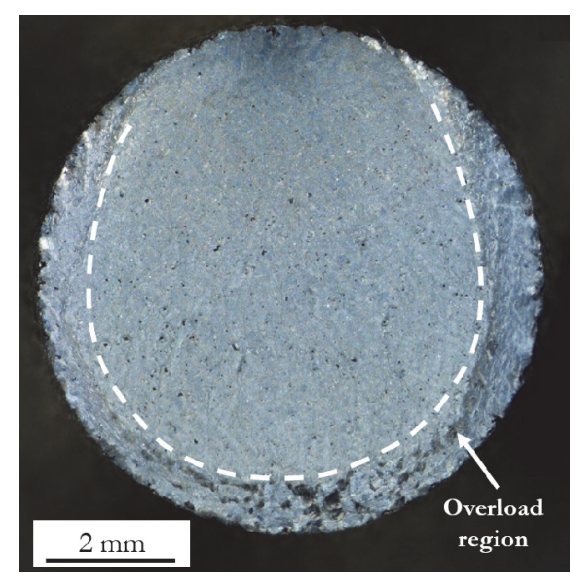

Figure 12: Digital microscope image of fatigue fracture surface.

In general, the fatigue fracture started from a single point at the surface or just below, where large porosities and/or lack of fusion defects were found (Fig. 13a-b). This is in agreement with the results of the analysis reported in Fig. 9, which shows that the largest defects (maximum Feret diameter) are located on an external layer of approximately $300 \mu \mathrm{m}$ thickness. Often, these imperfections were coupled with surface irregularities that increased the stress raiser effect (Fig. 14c-d). As already documented by roughness measurements in Tab. 3, the sand blasting has improved the surface quality of samples, however some local imperfections were not completely removed. It is evident from Fig. 14c-d that the size of sand-blasting particles used in this work is relatively small in comparison with the surface irregularities that should be flattened. The application of larger sand particles and higher pressures could be beneficial on fatigue strength by removing/reducing such local surface imperfections. This hypothesis seems to be confirmed by the results of the already mentioned work [2], on the effect of mechanical post-processing on fatigue resistance of DMLS AlSi10Mg alloy, where sand-blasting was performed at a pressure of $0.7 \mathrm{MPa}$ using particles with a diameter of $200-300 \mu \mathrm{m}$. In these conditions, the crack initiation sites moved from superficial to sub-superficial defects and the fatigue limit was much more enhanced in comparison with the present work. This despite the similar roughness values and superficial residual stresses measured after sand blasting. 

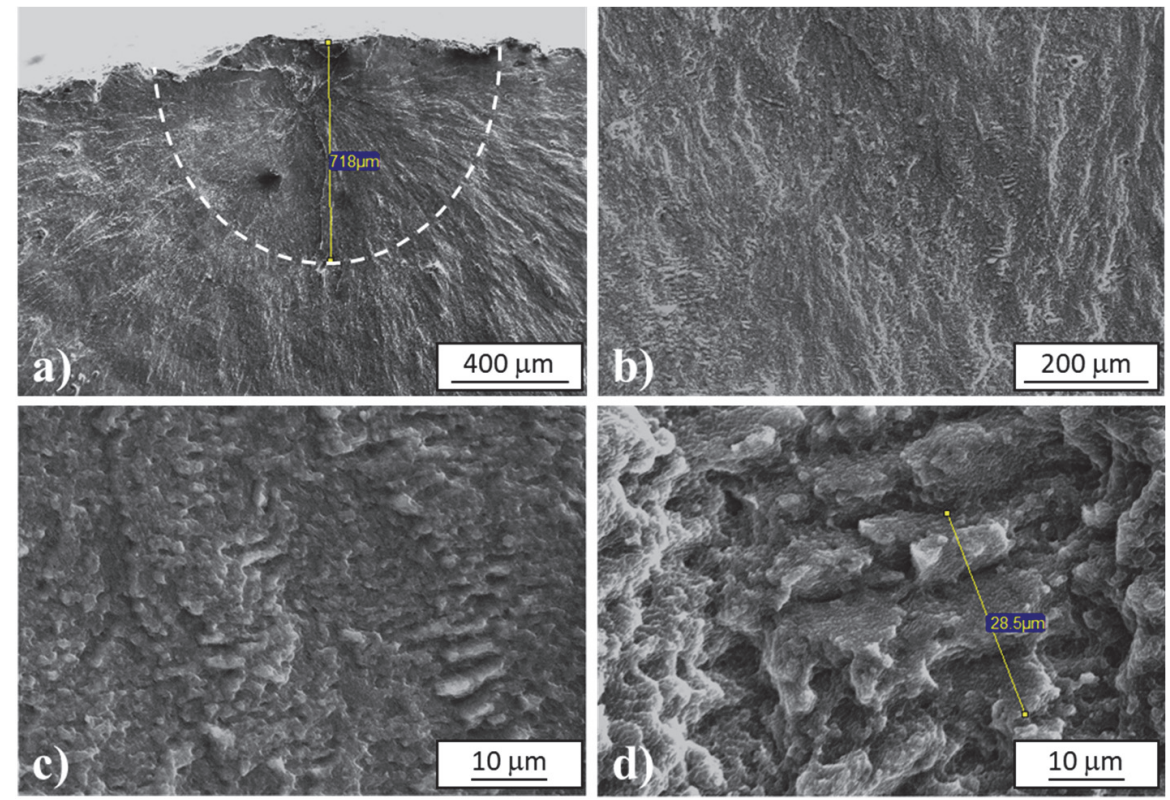

Figure 13: SEM images of different areas on fatigue fracture surface: a-c) close to the nucleation point and d) close to the end of the crack propagation region.
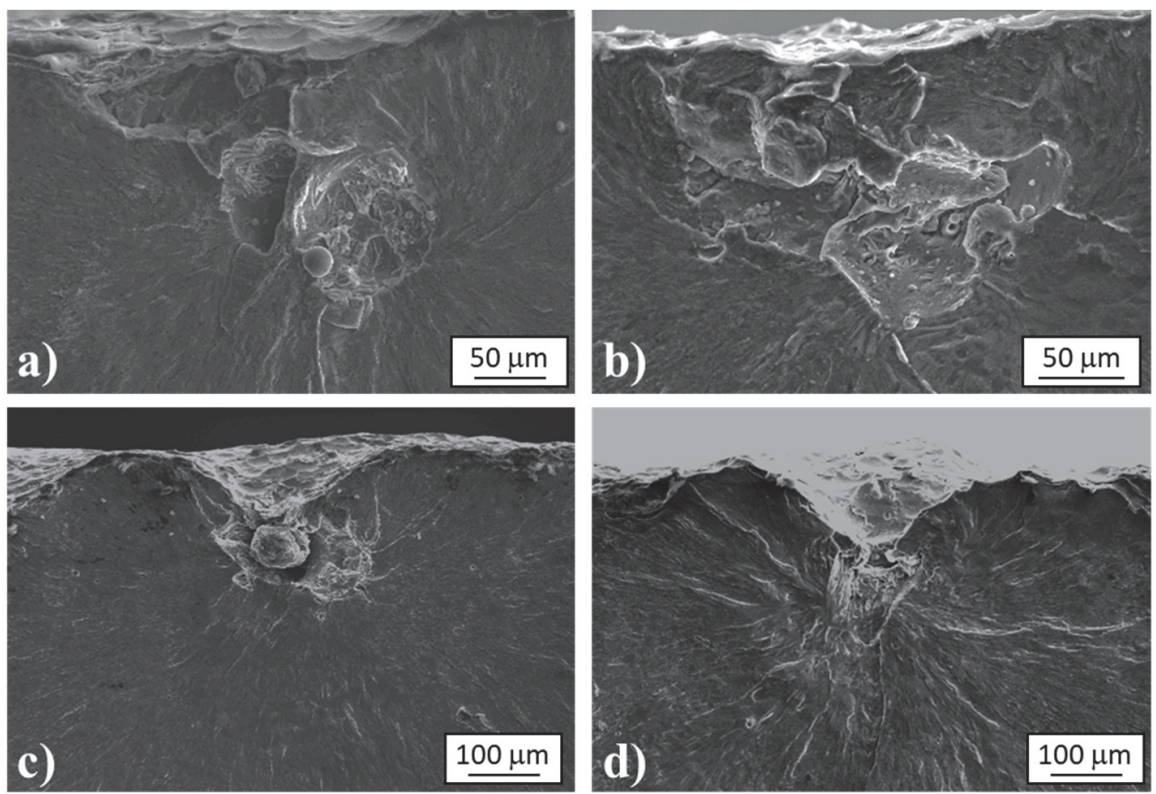

Figure 14: SEM images of the fracture surface showing the typical defects which started the failure: a) porosities, b) lack of fusion defects, c-d) defects coupled with surface micro-depressions.

\section{CONCLUSIONS}

7 he main aim of the present paper was the evaluation of the effect of sand-blasting on fatigue resistance of AlSi10Mg samples produced by DMLS. A preliminary characterization of sample surfaces was carried out before and after sand-blasting. It was found that this post-treatment is effective in reducing surface roughness and was also responsible for a change from tensile to compressive residual stresses on material surface. These results suggested a positive 
role of sand-blasting on fatigue resistance, which was experimentally demonstrated by the strength values obtained by axial fatigue tests.

A defects analysis was also performed and it allowed the identification of a uniform distribution of defects along the radial direction of the specimens in terms of both average size and number. On the other hand, it was also found that the most significant porosities in terms of maximum Feret diameter are located on an external layer with $300 \mu \mathrm{m}$ thickness for most of the investigated samples. This is in agreement with the observed fracture mechanism. In fact, superficial porosities acted as crack initiation sites, as evident from SEM analysis. In general, the propagation of the crack follows a flat surface with a small overload final region.

In conclusion, despite the fact that the residual defects on the sand-blasted surfaces are critical for crack initiation, sandblasting appears as an effective and relatively simple post-processing treatment to improve surface finishing and fatigue performance of the studied AlSi10Mg alloy.

\section{ACKNOWLEDGMENTS}

he authors wish to thank Bruker and Chem4Tech laboratory for the residual stress analysis, dr. L. Montesano for the support in SEM analysis.

\section{REFERENCES}

[1] Herzog, D., Seyda, V., Wycisk, E., Emmelmann, C. (2016). Additive manufacturing of metals, Acta Mater. 117, pp. 371392. DOI: $10.1016 /$ j.actamat.2016.07.019

[2] Sames, W. J., List, F. A., Pannala, S., Dehoff, R. R. (2016). The metallurgy and processing science of metal additive manufacturing, Int. Mater. Rev. 61 (5), pp. 315-360. DOI: 10.1080/09506608.2015.1116649.

[3] Petrovic, V., Vicente Haro Gonzalez, J., Jordá Ferrando, O., Delgado Gordillo, J., Ramon Blasco Puchades, J., Portoles Grinan, L. (2011). Additive layered manufacturing: Sectors of industrial application shown through case studies, Int. J. Prod. Res. 49(4), pp. 1061-1079. DOI: 10.1080/00207540903479786.

[4] Hitzler, L., Merkel, M., Hall, W., Ochsner, A. (2018). A Review of Metal Fabricated with Laser- and Powder-Bed Based Additive Manufacturing Techniques: Process Nomenclature, Materials, Achievable Properties, and its Utilization in the Medical Sector, Adv. Eng. Mater., pp. 1-28. DOI: 10.1002/adem.201700658.

[5] Tolosa, I., Garciandía, F., Zubiri, F. (2010). Study of mechanical properties of AISI 316 stainless steel processed by "selective laser melting", following different manufacturing strategies, Int. J. Adv. Manuf. Tech. 51 (5-9), pp. 639-647. DOI: $10.1007 /$ s00170-010-2631-5.

[6] Guan, K., Wang, Z., Gao, M., Li, X., Zeng, X. (2013). Effects of processing parameters on tensile properties of selective laser melted 304 stainless steel, Mater. Design 50, pp. 581-586, DOI: 10.1016/j.matdes.2013.03.056.

[7] Thijs, L., Verhaeghe, F., Craeghs, T., Humbeeck, J. V., Kruth, J.-P. (2010). A study of the microstructural evolution during selective laser melting of Ti-6Al-4V, Acta Mater., 58 (9), pp. 3303-3312. DOI: 10.1016/j.actamat.2010.02.004

[8] Vrancken, B., Thijs, L., Kruth, J.-P., Van Humbeeck, J. (2012). Heat treatment of Ti6Al4V produced by Selective Laser Melting: Microstructure and mechanical properties, J. Alloys Compd. 541 (15), pp. 177-185. DOI: $10.1016 /$ j.jallcom.2012.07.022.

[9] Demir, A. G., Previtali, B. (2017). Additive manufacturing of cardiovascular CoCr stents by selective laser melting, Mater. Design 119, pp. 338-350. DOI: 10.1016/j.matdes.2017.01.091.

[10] Jia, Q., Gu, D. (2014). Selective laser melting additive manufacturing of Inconel 718 superalloy parts: Densification, microstructure and properties, J. Alloys Compd. 585, pp. 713-721. DOI: 10.1016/j.jallcom.2013.09.171.

[11] Kanagarajah, P., Brenne, F., Niendorf, T., Maier, H. J. (2013). Inconel 939 processed by selective laser melting: Effect of microstructure and temperature on the mechanical properties under static and cyclic loading, Mat. Sci. Eng. A-Struct. 213, 588, pp. 188-195. DOI: 10.1016/j.msea.2013.09.025.

[12] Liu, Z. H., Zhang, D. Q., Sing, S. L. . C. C. K., Loh, L. E. (2014). Interfacial characterization of SLM parts in multimaterial processing: Metallurgical diffusion between 316L stainless steel and C18400 copper alloy, Mater. Charact. 94, pp. 116-125. DOI: 10.1016/j.matchar.2014.05.001. 
[13] Scudino, S., Unterdörfer, C., Prashanth, K. G., Attar, H., Ellendt, N., Uhlenwinkel, V., Eckert, J. (2015). Additive manufacturing of $\mathrm{Cu}-10 \mathrm{Sn}$ bronze, Mater. Lett. 156, pp. 202-204. DOI: 10.1016/j.matlet.2015.05.076.

[14] Louvis, E., Fox, P., Sutcliffe, C. J. (2011). Selective laser melting of aluminium components, J. Mater. Process. Tech. 211(2), pp. 275-284. DOI: 10.1016/j.jmatprotec.2010.09.019.

[15] Aboulkhair, N. T., Everitt, N. M., Ashcroft, I., Tuck, C. (2014). Reducing porosity in AlSi10Mg parts processed by selective laser melting, Addit. Manuf. 1, pp. 77-86. DOI: 10.1016/j.addma.2014.08.001.

[16] Khan, M., Dickens, P. (2010). Selective Laser Melting (SLM) of pure gold, Gold Bull. 43 (2), pp. 114-121. DOI: $10.1007 / \mathrm{BF} 03214976$.

[17] Read, N., Wang, W., Essa, K., Attallah, M. M. (2015). Selective laser melting of AlSi10Mg alloy: Process optimisation and mechanical properties development, Mater. Design 65, pp. 417-424. DOI: 10.1016/j.matdes.2014.09.044.

[18] Thijs, L., Kempen, K., Kruth, J.-P., Humbeeck, J. V. (2013). Fine-structured aluminium products with controllable texture by selective laser melting of pre-alloyed AlSi10Mg powder, Acta Mater. 61, pp. 1809-1819.

DOI: 10.1016/j.actamat.2012.11.052.

[19] Martin, J. H., Yahata, B. D., Hundley, J. M., Mayer, J. A., Schaedler, T. A., Pollock, T. M. (2017). 3D printing of highstrength aluminium alloys, Nature, 549 (7672), pp. 365-369. DOI: 10.1038/nature23894.

[20] Ghidini, T., Pambaguian, L., Blair, S. (2015). Joining the third industrial revolution: 3D printing for space, European Space Agency Bulletin, 163, pp. 24-33.

[21] Aboulkhair, N. T., Maskery, I., Tuck, C., Ashcroft, I., Everitt, N. M. (2016). The microstructure and mechanical properties of selectively laser melted AlSi10Mg: The effect of a conventional T6-like heat treatment, Mater. Sci. Eng. A-Struct. 667, pp. 139-146. DOI: 10.1016/j.msea.2016.04.092.

[22] Li, W., Li, S., Liu, J., Zhang, A., Zhou, Y., Wei, Q., Yan, C., Shi, Y. (2016). Effect of heat treatment on AlSi10Mg alloy fabricated by selective laser melting: Microstructure evolution, mechanical properties and fracture mechanism, Mater. Sci. Eng. A-Struct. 663, pp. 116-125. DOI: 10.1016/j.msea.2016.03.088.

[23] Aboulkhair, N. T., Tuck, C., Ashcroft, I., Maskery, I., Everitt, N. M. (2015). On the Precipitation Hardening of Selective Laser Melted AlSi10Mg, Metall. Mater. Trans. A, 46A, pp. 3337-3341. DOI: 10.1007/s11661-015-2980-7.

[24] Kempen, K., Thijs, L., Van Humbeeck, J., Kruth, J.-P. (2012). Mechanical properties of AlSi10Mg produced by Selective Laser Melting, Physics Proc. 39, pp. 439-446. DOI: 10.1016/j.phpro.2012.10.059.

[25] Wu, J., Wang, X.Q., Wang, W., Attallah, M.M., Loretto, M.H. (2016). Microstructure and strength of selectively laser melted AlSi10Mg, Acta Mater. 117, pp. 311-320. DOI: 10.1016/j.actamat.2016.07.012.

[26] Brandl, E., Heckenberger, U., Holzinger, V., Buchbinder, D. (2012). Additive manufactured AlSi10Mg samples using Selective Laser Melting (SLM): Microstructure, high cycle fatigue, and fracture behavior, Mater. Design 34, pp. 159-169. DOI: 10.1016/j.matdes.2011.07.067.

[27] Girelli, L., Tocci, M., Conte, M., Giovanardi, R., Veronesi, P., Gelfi, M., Pola, A. (2019). Effect of the T6 heat treatment on corrosion behavior of additive manufactured and gravity cast AlSi10Mg alloy, Mater. Corros., pp. 1-9.

DOI: $10.1002 /$ maco.201910890.

[28] Cabrini, M., Lorenzi, S., Pastore, T., Pellegrini, S., Pavese, M., Fino, P., Ambrosio, E. P., Calignano, F., Manfredi, D. (2016). Corrosion resistance of direct metal laser sintering AlSiMg alloy, Surf. Interface Anal., 48, pp. 818-826. DOI: $10.1002 /$ sia.5981.

[29] Cabrini, M., Lorenzi, S., Pastore, T., Pellegrini, S., Manfredi, D., Fino, P., Biamino, S., Badini, C. (2016). Evaluation of corrosion resistance of Al-10Si-Mg alloy obtained by means of Direct Metal Laser Sintering, Journal of Materials Processing Technology 231, pp. 326-335. DOI: 10.1016/j.jmatprotec.2015.12.033

[30] Uzan, N.E., Shneck, R., Yeheskel, O., Frage, N. (2017). Fatigue of AlSi10Mg specimens fabricated by additive manufacturing selective laser melting (AM-SLM), Mat. Sci. Eng. A 704, pp. 229-237. DOI: 10.1016/j.msea.2017.08.027.

[31] Domfang Ngnekou, J. N., Nadot, Y., Henaff, G., Nicolai, J., Ridosz, L. (2017). Influence of defect size on the fatigue resistance of AlSi10Mg alloy elaborated by selective laser melting (SLM), Procedia Struct. Integrity 7, pp. 75-83. DOI: $10.1016 /$ j.prostr.2017.11.063.

[32] Domfang Ngnekou, J.N., Nadot, Y., Henaff, G., Nicolai, J., Kan, W.H., Cairney, J.M., Ridosz, L. (2019). Fatigue properties of AlSi10Mg produced by Additive Layer Manufacturing, Int. J. Fatigue 119, pp. 160-172.

DOI: 10.1016/j.ijfatigue.2018.09.029.

[33] Girelli, L., Tocci, M., Montesano, L., Gelfi, M., Pola, A. (2017). Optimization of heat treatment parameters for additive manufacturing and gravity casting AlSi10Mg alloy, IOP Conf. Ser. Mater. Sci. Eng., 264, pp. 1-8.

DOI: $10.1088 / 1757-899 \mathrm{X} / 264 / 1 / 012016$. 
[34] Girelli, L., Giovagnoli, M., Tocci, M., Pola, A., Fortini, A., Merlin, M., La Vecchia, G. M. (2019). Evaluation of the impact behaviour of AlSi10Mg alloy produced using laser additive manufacturing, Mater. Sci. Eng. A-Struct., 748, pp. 38-51. DOI: 10.1016/j.msea.2019.01.078.

[35] Maskery, I., Aboulkhair, N., Corfield, M., Tuck, C., Clare, A., Leach, R., Wildman, R., Ashcroft, I., Hague, R. (2016). Quantification and characterisation of porosity in selectively laser melted Al-Sil0-Mg using X-ray computed tomography, Mater. Charact. 111, pp. 193-204. DOI: 10.1016/j.matchar.2015.12.001.

[36] Zhang, B., Li, Y., Bai, Q. (2017). Defect Formation Mechanisms in Selective Laser Melting: A Review, Chin. J. Mech. Eng. (English Ed.) 30 (3), pp. 515-527. DOI: 10.1007/s10033-017-0121-5.

[37] Mercelis, P., Kruth, J.-P. (2006). Residual stresses in selective laser sintering and selective laser melting, Rapid Prototyping J. 12 (5), pp. 254-265. DOI: 10.1108/13552540610707013.

[38] Zaeh, M. F., Branner, G. (2010). Investigations on residual stresses and deformations in selective laser melting, Prod. Engineer. 4 (1), pp. 35-45. DOI: 10.1007/s11740-009-0192-y.

[39] Strano, G., Hao, L., Everson, R. M., Evans, K. E. (2013). Surface roughness analysis, modelling and prediction in selective laser melting, J. Mater. Process. Tech. 213 (4), pp. 589-597. DOI: 10.1016/j.jmatprotec.2012.11.011.

[40] Gu, D., Shen, Y. (2009). Balling phenomena in direct laser sintering of stainless steel powder: metallurgical mechanisms and control methods, Mater. Design, 30 (8), pp. 2903-2910. DOI: 10.1016/j.matdes.2009.01.013.

[41] Romano, S., Brückner-Foit, A., Brandão, A., Gumpinger, J., Ghidini, T., Beretta, S. (2018). Fatigue properties of AlSi10Mg obtained by additive manufacturing: Defect-based modelling and prediction of fatigue strength, Eng. Fract. Mech. 187, pp. 165-189. DOI: 10.1016/j.engfracmech.2017.11.002.

[42] Yadollahi, A., Shamsaei, N. (2017). Additive manufacturing of fatigue resistant materials: Challenges and opportunities. Int. J. Fatigue 98, 14-31, 98, pp. 14-30. DOI: 10.1016/j.ijfatigue.2017.01.001.

[43] Aboulkhair, N. T., Maskery, I., Tuck, C., Ashcroft, I., Everitt, N. M. (2016). Improving the fatigue behaviour of a selectively laser melted aluminium alloy: Influence of heat treatment and surface quality, Mat. Des. 104, pp. 174-182. DOI: $10.1016 /$ j.matdes.2016.05.041.

[44] Uzan, N. E., Ramati, S., Shneck, R., Frage, N., Yeheskel, O. (2018). On the effect of shot-peening on fatigue resistance of AlSi10Mg specimens fabricated by additive manufacturing using selective laser melting (AM-SLM), Addit. Manuf. 21, pp. 458-464. DOI: 10.1016/j.addma.2018.03.030.

[45] Bagherifad, S., Beretta, N., Monti, S., Riccio, M., Bandini, M., Guagliano, M. (2018). On the fatigue strength enhancement of additive manufactured AlSi10Mg parts by mechanical and thermal post-processing, Mater. Design, 145, pp. 28-41. DOI: 10.1016/j.matdes.2018.02.055.

[46] Damon, J., Dietrich, S., Vollert, F., Gibmeier, J., Schulze, V. (2018). Process dependent porosity and the influence of shot peening on porosity morphology regarding selective laser melted AlSi10Mg parts, Addit. Manuf., 20, pp. 77-89. DOI: 0.1016/j.addma.2018.01.001

[47] EOS GmbH Electro Optical System. EOS GmbH Electro Optical System. http://www.eos.info/eos-m290 (accessed on 29, March 2019).

[48] ASTM. ASTM E407. Standard practice for microetching metals and alloys.

[49] Avanzini, A., Battini, D. (2016). Integrated experimental and numerical comparison of different approaches for planar biaxial testing of a hyperelastic material, Adv. Mater. Sc. Eng., No. ID 6014129. DOI: 10.1155/2016/6014129.

[50] Avanzini, A., Petrogalli, C., Battini, D., Donzella, G. (2018). Influence of micro-notches on the fatigue strength and crack propagation of unfilled and short carbon fiber reinforced PEEK, Mater. Design, 139, pp. 447-456. DOI: $10.1016 /$ j.matdes.2017.11.039.

[51] Lee, Y., Pan, J., Hathaway, R. B., Barkey, M. E. Fatigue Testing and Analysis, Elsevier, p.108, 2005.

[52] Nazakawa, H., Kodama, S. Statistical S-N testing method with 14 specimens: JSME standard method for determination of S-N curve. In Statistical Research on Fatigue and Fracture - Current Japanese Materials Research - Vol. 2, Tanaka T, Nishijima S, Ichikawa M Eds., 1987, pp. 55-69.

[53] Liu, X., Zhao, C., Zhou, X., Shen, Z, Liu, W. (2019). Microstructure of selective laser melted AlSi10Mg alloy, Mater. Design, 168 (107677). DOI: 10.1016/j.matdes.2019.107677.

[54] Girelli, L., Tocci, M., Gelfi, M., Pola, A. (2019). Study of heat treatment parameters for additively manufactured AlSi10Mg in comparison with corresponding cast alloy, Mat. Sci. Eng. A 739, pp. 317-328.

DOI: $10.1016 /$ j.msea.2018.10.026.

[55] Frazler, W. E. (2014). Metal Additive Manufacturing: A Review. JMEPEG, 23, pp. 1917-1928. DOI: $10.1007 /$ s11665-014-0958-z.

[56] Ng, G. K. L., Jarfors, A. E. W., Bi, G., Zheng, H. Y. (2009). Porosity formation and gas bubble retention in laser metal, Appl. Phys. A-Mater. 97 (3), pp. 641-649. DOI: 10.1007/s00339-009-5266-3. 
[57] Mower, T. M., Long, M. J. (2016). Mechanical behavior of additive manufactured, powder-bed laser-fused materials, Mat. Sci. Eng. A, 651, pp. 198-213. DOI: 10.1016/j.msea.2015.10.068.

[58] Tang, M., Pistorius, P. C. (2017). Oxides, porosity and fatigue performance of AlSi10Mg parts produced by selective laser melting, Int. J. Fatigue 94, pp. 192-201. DOI: 10.1016/j.ijfatigue.2016.06.002.

[59] Stephens, R. I., Fatemi, A., Stephens, R. R., Fuchs, H. O. Metal Fatigue in Engineering, John Wiley \& Sons, 2001. 